\title{
A Randomized Trial of Multivitamin Supplements and HIV Disease Progression and Mortality
}

\section{Citation}

Fawzi, Wafaie W., Gernard I. Msamanga, Donna Spiegelman, Ruilan Wei, Saidi Kapiga, Eduardo Villamor, Davis Mwakagile, et al. 2004. "A Randomized Trial of Multivitamin Supplements and HIV Disease Progression and Mortality." New England Journal of Medicine 351 (1): 23-32. https:// doi.org/10.1056/nejmoa040541.

\section{Permanent link}

http://nrs.harvard.edu/urn-3:HUL.InstRepos:41384714

\section{Terms of Use}

This article was downloaded from Harvard University's DASH repository, and is made available under the terms and conditions applicable to Other Posted Material, as set forth at http:// nrs.harvard.edu/urn-3:HUL.InstRepos:dash.current.terms-of-use\#LAA

\section{Share Your Story}

The Harvard community has made this article openly available. Please share how this access benefits you. Submit a story.

Accessibility 


\section{A Randomized Trial of Multivitamin Supplements and HIV Disease Progression and Mortality}

\author{
Wafaie W. Fawzi, M.B., B.S., Dr.P.H., Gernard I. Msamanga, M.D., Sc.D., \\ Donna Spiegelman, Sc.D., Ruilan Wei, Ph.D., Saidi Kapiga, M.D., Sc.D., \\ Eduardo Villamor, M.D., Dr.P.H., Davis Mwakagile, M.D., M.Med., \\ Ferdinand Mugusi, M.D., M.Med., Ellen Hertzmark, M.A., \\ Max Essex, D.V.M., Ph.D., and David J. Hunter, M.B., B.S., Sc.D.
}

ABSTRACT

BACKGROUN D

Results from observational studies suggest that micronutrient status is a determinant of the progression of human immunodeficiency virus (HIV) disease.

\section{METHODS}

We enrolled 1078 pregnant women infected with HIV in a double-blind, placebo-controlled trial in Dar es Salaam, Tanzania, to examine the effects of daily supplements of vitamin A (preformed vitamin A and beta carotene), multivitamins (vitamins B, C, and E), or both on progression of HIV disease, using survival models. The median follow-up with respect to survival was 71 months (interquartile range, 46 to 80 ).

\section{RESULTS}

Of 271 women who received multivitamins, 67 had progression to World Health Organization (WHO) stage 4 disease or died - the primary outcome - as compared with 83 of 267 women who received placebo (24.7 percent vs. 31.1 percent; relative risk, 0.71 ; 95 percent confidence interval, 0.51 to $0.98 ; \mathrm{P}=0.04)$. This regimen was also associated with reductions in the relative risk of death related to the acquired immunodeficiency syndrome $(0.73$; 95 percent confidence interval, 0.51 to $1.04 ; \mathrm{P}=0.09)$, progression to WHO stage $4(0.50 ; 95$ percent confidence interval, 0.28 to $0.90 ; \mathrm{P}=0.02)$, or progression to stage 3 or higher $(0.72 ; 95$ percent confidence interval, 0.58 to 0.90 ; $\mathrm{P}=0.003)$. Multivitamins also resulted in significantly higher CD4+ and CD8+ cell counts and significantly lower viral loads. The effects of receiving vitamin A alone were smaller and for the most part not significantly different from those produced by placebo. Adding vitamin A to the multivitamin regimen reduced the benefit with regard to some of the end points examined.

\section{CONCLUSIONS}

Multivitamin supplements delay the progression of HIV disease and provide an effective, low-cost means of delaying the initiation of antiretroviral therapy in HIV-infected women.
From the Departments of Nutrition (W.W.F. R.W., E.V., D.J.H.), Epidemiology (W.W.F., D.S., E.H., D.J.H.), Biostatistics (D.S.), Population and International Health (S.K.), and Immunology and Infectious Diseases (M.E.), Harvard School of Public Health, Boston; and the Departments of Community Health (G.I.M.), Microbiology and Immunology (D.M.), and Internal Medicine (F.M.), Muhimbili University College of Health Sciences, Dar es Salaam, Tanzania. Address reprint requests to Dr. Fawzi at the Department of Nutrition, Harvard School of Public Health, 665 Huntington Ave., Boston, MA 02115, or at mina@hsph. harvard.edu.

N EnglJ Med 2004;351:23-32.

Copyright $(2004$ Massachusetts Medical Society. 


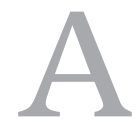

T THE END OF 2003, APPROXIMATELY 40 million people worldwide were infected with human immunodeficiency virus (HIV), many of whom had symptoms of the acquired immunodeficiency syndrome (AIDS). ${ }^{1} \mathrm{Few}$ er than 8 percent of the 6 million patients with advanced disease who were eligible for antiretroviral treatment were receiving it. The "Treat 3 Million by 2005" initiative of the World Health Organization (WHO) is designed to increase access to treatment. ${ }^{2}$ According to this plan and country-specific standards of care, patients with advanced disease will receive antiretroviral treatment, while those in earlier stages will be monitored and given supportive care.

Micronutrient supplements have been proposed as low-cost immunomodulating interventions that may slow the progression of HIV disease. ${ }^{3,4}$ If efficacious, supplements could delay the onset of advanced disease and the need for antiretroviral therapy, saving antiretroviral drugs for when they may be most needed and reducing drug-related adverse events and costs. Therefore, we examined the effect of micronutrient supplements - vitamin A alone, multivitamins including vitamin $\mathrm{B}$ complex and vitamins $\mathrm{C}$ and $\mathrm{E}$, and multivitamins plus vitamin $\mathrm{A}$ - on the risks of clinical disease progression, HIV-related complications, CD4+ cell counts, and viral load in HIV-positive women in Tanzania.

\section{METHODS}

We enrolled 1078 HIV-infected pregnant women in Dar es Salaam, Tanzania, over a two-year period starting in April 1995. Women were followed from enrollment until the end of the study in August 2003. The design of the trial has been described in detail (the randomization scheme and outcomes are shown in the Supplementary Appendix, available with the full text of this article at www. nejm.org). ${ }^{5}$ In brief, eligible women were randomly assigned in blocks of 20 to receive a daily oral dose of one of four regimens for the duration of follow-up: vitamin A alone ( $30 \mathrm{mg}$ of beta carotene plus 5000 IU of preformed vitamin A), multivitamins excluding vitamin $A\left(20 \mathrm{mg}\right.$ of vitamin $B_{1}$, $20 \mathrm{mg}$ of vitamin $\mathrm{B}_{2}, 25 \mathrm{mg}$ of vitamin $\mathrm{B}_{6}, 100 \mathrm{mg}$ of niacin, $50 \mu \mathrm{g}$ of vitamin $\mathrm{B}_{12}, 500 \mathrm{mg}$ of vitamin $\mathrm{C}$, $30 \mathrm{mg}$ of vitamin $\mathrm{E}$, and $0.8 \mathrm{mg}$ of folic acid), multivitamins plus vitamin $\mathrm{A}$ in the same doses listed above, or placebo. All women received standard doses of antenatal folic acid and iron. At delivery, women in the two groups that received vitamin $\mathrm{A}$ were given an additional oral dose of vitamin A (200,000 IU), whereas the women in the other two groups were given a placebo. All children received a dose of vitamin A every six months, according to the standard of care in Tanzania. Active tablets and placebo were identical in size and color. All clinical and follow-up staff were unaware of the women's treatment assignments. At the time of the study, antiretroviral therapy was not available to the majority of women in Tanzania, including those who participated in the study.

Women were followed through monthly visits to a study clinic, where physicians performed a physical examination. A study nurse inquired about the health of the woman in the preceding period, including signs of HIV-related complications. Diarrhea was defined as three or more watery stools in the prior 24 hours. Dysentery was defined as an episode of diarrhea with mucus or blood. Weight, height, and the circumference of the middle of the upper arm were determined. The stage of HIV was assessed at each visit in accordance with the WHO criteria on the basis of the woman's history and physical examination. ${ }^{6}$ For women who did not attend the clinic or who traveled out of Dar es Salaam, a home visit was made and neighbors or relatives were asked about vital status. No data on complications were collected at these visits. To approximate the cause of death, we used verbal-autopsy techniques by conducting standardized interviews with relatives, reviewing medical records, or both. The cause of death was ascertained in a blinded fashion. Data on women whose cause of death could not be ascertained or for whom death was deemed unrelated to AIDS were censored at the time of death. A total of 343 women died during follow-up. Of these deaths, 243 were deemed to be due or related to AIDS: 82 were due to AIDS, 61 to pulmonary tuberculosis, 3 to extrapulmonary tuberculosis, 10 to anemia, 14 to meningitis, 5 to stroke, 23 to pneumonia, 21 to diarrhea, and 24 to fever. Because enrollment occurred over a period of two years, the maximal duration of follow-up for each woman varied accordingly. The median duration of follow-up with respect to survival was 71 months (interquartile range, 46 to 80 ).

A blood specimen was requested at baseline and every six months thereafter for the measurement of T-cell subgroups (CD4+, CD8+, and CD3+) with the use of the FACScount and FACSCAN systems (Becton Dickinson). A mean ( $\pm S D$ ) of $7.8 \pm 4.9$ measurements were available for each woman (median, 
8). We selected a random sample of 300 women to examine the effect of supplements on viral load. For these women, a minimum of three blood samples (baseline, last sample at the time of selection, and the sample at approximately the midpoint between the two) were analyzed. Data from a small, previously analyzed subgroup were included; thus, some women contributed more than three specimens to the analysis. For women who died, we used the last sample that had been obtained at least six months before death as the final sample to avoid using specimens obtained during terminal illness. The data set for the final analysis comprised 1051 specimens from 297 women who had adequate baseline specimens and at least one or more viral-load measurements. Viral load was quantified with the use of the Roche Amplicor version 1.5 assay. A mean of $2.8 \pm 1.5$ measurements were available for each woman (median, 3). The number of women and the average number of measurements of viral load per woman were similar in the four groups $(\mathrm{P}=0.89$ and $\mathrm{P}=0.88$, respectively).

The primary aims were to compare the effects of multivitamins, vitamin A alone, and both with those of placebo. A factorial design was used to maximize statistical power. The sample size was calculated to examine the efficacy of the supplements on mother-to-child (vertical) transmission of HIV and on disease progression, assuming a 30 percent incidence of each outcome. Given the primary aims specified in the original protocol, we examined as the primary strategy the effects of each treatment on disease progression, as compared with those of placebo. Also, given our subsequent observation of a significantly higher risk of vertical transmission of HIV type 1 among women receiving vitamin $\mathrm{A},{ }^{7,8}$ the remaining question of interest with respect to public health was the efficacy of multivitamins as compared with that of placebo.

We compared baseline characteristics in the four groups using an F test (SAS GLM procedure) for continuous variables and the chi-square test for categorical variables. We used proportional-hazards regression models to investigate the effects of the supplements on the time to the predefined primary clinical outcome of progression to WHO stage 4 or death from AIDS-related causes, whichever occurred first. ${ }^{9}$ We also compared the times to the following end points: death from AIDS-related causes, progression to WHO stage 4, progression to WHO stage 3 or higher, or an increase of at least two stages from baseline. For these outcomes, fol- low-up ended on the date on which the stage was last assessed. One woman in WHO stage 4 at randomization was excluded from these analyses. We also examined whether the effects of the regimens on the primary end point were modified by maternal baseline characteristics dichotomized using conventional cutoff points for CD4+ cells (fewer than 350 vs. at least 350 per cubic millimeter) and plasma vitamin A (less than $0.7 \mu \mathrm{mol}$ per liter vs. at least $0.7 \mu \mathrm{mol}$ per liter), or the median value of plasma vitamin $\mathrm{E}$ (less than $9.7 \mu \mathrm{mol}$ per liter vs. at least $9.7 \mu \mathrm{mol}$ per liter) and the circumference of the middle of the upper arm $(25 \mathrm{~cm})$ as another marker of maternal nutritional status.

We compared effects of the supplements on T-cell counts (CD4+, CD8+, and CD3+), viral load, and individual signs of disease, including conditions ascertained by study physicians at clinic visits, such as thrush, gingival erythema, angular cheilitis, oral ulcers, and acute upper respiratory tract infection. Clinical signs reported during the month before visits included ulcers in the mouth and throat, painful tongue or mouth, difficult or painful swallowing, nausea and vomiting, diarrhea, dysentery, fatigue, and rash. Effects of supplements on complications, T-cell counts, and viral load were analyzed with the use of generalized estimating equations and SAS Proc Genmod software. ${ }^{10}$

To assess the effectiveness of treatment over time, we analyzed data for the whole period, the first two years, and the first four years. A data and safety monitoring board reviewed the progress of the study and the results of interim analyses. Given earlier findings from the trial indicating beneficial effects of the multivitamin regimen in reducing adverse outcomes of pregnancy, ${ }^{11}$ all women who became pregnant after May 1998 were given openlabel multivitamins throughout pregnancy; these women reverted to their prepregnancy blinded regimen after delivery. In September 2000, the data and safety monitoring board recommended that vitamin A be dropped from the two vitamin A-containing regimens because increased transmission of HIV to children was found to be associated with maternal vitamin A supplementation. ${ }^{7}$ Subsequently, women randomly assigned to receive vitamin A alone or with multivitamins received placebo alone or with multivitamins, respectively. All analyses were conducted according to the intention to treat, and $\mathrm{P}$ values are two-sided. We performed secondary analyses censoring all data on September 30, 2000 , the date the data and safety monitoring board 
recommended dropping the vitamin A treatment. The results were essentially the same; hence, only primary analyses are presented.

All women gave oral or written informed consent to participate in the study according to a strict protocol that was approved by the institutional review boards. The institutional review boards of Muhimbili University College of Health Sciences, the Tanzanian National AIDS Control Program, and Harvard School of Public Health approved the study protocol. None of the sponsors of the study had any role in the study design, data collection, data analysis, data interpretation, or writing of the report.

\section{RESULTS}

The baseline characteristics of the four groups were similar, including age, level of education, he- moglobin levels, CD4+ and CD8+ cell counts, and plasma levels of vitamins A and E (Table 1). Compliance, evaluated as the number of tablets absent from the returned bottles at monthly visits divided by the total number of tablets the woman should have taken, was high: 79 percent over the total period of follow-up, 83 percent at two years, and 80 percent at four years. Compliance was similar in all groups.

A total of 299 of the 1078 women progressed to WHO stage 4 or died of AIDS-related causes: 67 of 271 women who received multivitamins (24.7 percent), 70 of 268 who received multivitamins plus vitamin $A$ ( 26.1 percent), 79 of 272 who received vitamin A alone (29.0 percent), and 83 of 267 women who received placebo (31.1 percent) (Table 2). As compared with women in the placebo group, those in the multivitamin group were significantly

\begin{tabular}{|c|c|c|c|c|}
\hline Characteristic & Placebo $(\mathrm{N}=267)$ & $\begin{array}{l}\text { Multivitamins } \\
\quad(\mathrm{N}=\mathbf{2 7 1})\end{array}$ & $\begin{array}{l}\text { Multivitamins + Vitamin A } \\
\qquad(\mathrm{N}=\mathbf{2 6 8})\end{array}$ & $\begin{array}{l}\text { Vitamin A Alone } \\
\qquad(\mathrm{N}=\mathbf{2 7 2})\end{array}$ \\
\hline Age (yr) & $24.7 \pm 4.7$ & $24.6 \pm 4.8$ & $24.8 \pm 4.6$ & $24.6 \pm 5.0$ \\
\hline $\begin{array}{l}\text { Level of education (\%) } \\
\text { None or adult education } \\
1-4 \mathrm{yr} \\
5-8 \mathrm{yr} \\
>8 \mathrm{yr}\end{array}$ & $\begin{array}{r}8.3 \\
5.6 \\
79.0 \\
7.1\end{array}$ & $\begin{array}{r}10.3 \\
6.3 \\
72.7 \\
10.7\end{array}$ & $\begin{array}{r}7.1 \\
3.7 \\
77.3 \\
11.9\end{array}$ & $\begin{array}{r}7.4 \\
4.4 \\
77.9 \\
10.3\end{array}$ \\
\hline $\begin{array}{l}\text { Prior pregnancies (\%) } \\
0 \\
1-3 \\
>3\end{array}$ & $\begin{array}{l}23.6 \\
60.4 \\
16.0\end{array}$ & $\begin{array}{l}30.2 \\
57.2 \\
12.6\end{array}$ & $\begin{array}{l}23.0 \\
63.4 \\
13.6\end{array}$ & $\begin{array}{l}29.0 \\
54.7 \\
16.3\end{array}$ \\
\hline $\begin{array}{l}\text { WHO disease stage (\%) } \\
\qquad \begin{array}{l}1 \\
2 \\
3\end{array}\end{array}$ & $\begin{array}{r}82.4 \\
16.1 \\
1.5\end{array}$ & $\begin{array}{c}81.8 \\
18.2 \\
0\end{array}$ & $\begin{array}{r}80.4 \\
18.1 \\
1.5\end{array}$ & $\begin{array}{r}77.8 \\
19.6 \\
2.6\end{array}$ \\
\hline $\begin{array}{c}\text { CD4+ cell count (\%) } \\
0 \text { to } 199 / \mathrm{mm}^{3} \\
200 \text { to } 349 / \mathrm{mm}^{3} \\
\geq 350 / \mathrm{mm}^{3}\end{array}$ & $\begin{array}{l}13.9 \\
21.7 \\
64.4\end{array}$ & $\begin{array}{l}11.8 \\
21.2 \\
67.0\end{array}$ & $\begin{array}{l}13.5 \\
26.6 \\
59.9\end{array}$ & $\begin{array}{l}12.0 \\
28.2 \\
59.8\end{array}$ \\
\hline Circumference of middle of upper arm $(\mathrm{cm})$ & $25.4 \pm 2.9$ & $25.7 \pm 2.9$ & $25.5 \pm 2.8$ & $25.6 \pm 3.0$ \\
\hline CD4+ cell count $/ \mathrm{mm}^{3}$ & $429 \pm 224$ & $433 \pm 199$ & $411 \pm 205$ & $417 \pm 201$ \\
\hline CD8+ cell count $/ \mathrm{mm}^{3}$ & $770 \pm 363$ & $739 \pm 329$ & $1223 \pm 446$ & $748 \pm 313$ \\
\hline $\mathrm{CD} 3+$ cell count $/ \mathrm{mm}^{3}$ & $1260 \pm 504$ & $1226 \pm 445$ & $1223 \pm 446$ & $1225 \pm 434$ \\
\hline Erythrocyte sedimentation rate $(\mathrm{mm} / \mathrm{hr})$ & $62.6 \pm 37.9$ & $57.8 \pm 36.3$ & $58.0 \pm 34.7$ & $56.7 \pm 35.4$ \\
\hline Viral load $(\log ) \dagger$ & $4.58 \pm 0.89$ & $4.56 \pm 0.78$ & $4.62 \pm 0.83$ & $4.66 \pm 0.77$ \\
\hline Hemoglobin (g/liter) & $96 \pm 17$ & $93 \pm 16$ & $93 \pm 16$ & $94 \pm 17$ \\
\hline Plasma vitamin A ( $\mu \mathrm{mol} /$ liter $)$ & $0.88 \pm 0.42$ & $0.85 \pm 0.34$ & $0.87 \pm 0.31$ & $0.85 \pm 0.34$ \\
\hline Plasma vitamin $\mathrm{E}(\mu \mathrm{mol} /$ liter $)$ & $10.0 \pm 3.1$ & $10.0 \pm 3.0$ & $10.2 \pm 3.0$ & $9.9 \pm 3.2$ \\
\hline
\end{tabular}

* Plus-minus values are means \pm SD. There were no significant differences among the groups.

$\dagger$ Data on viral load were available for 300 randomly selected women and an additional 115 women (from a previously analyzed subgroup) for whom baseline values were measured. A base-10 scale was used. 


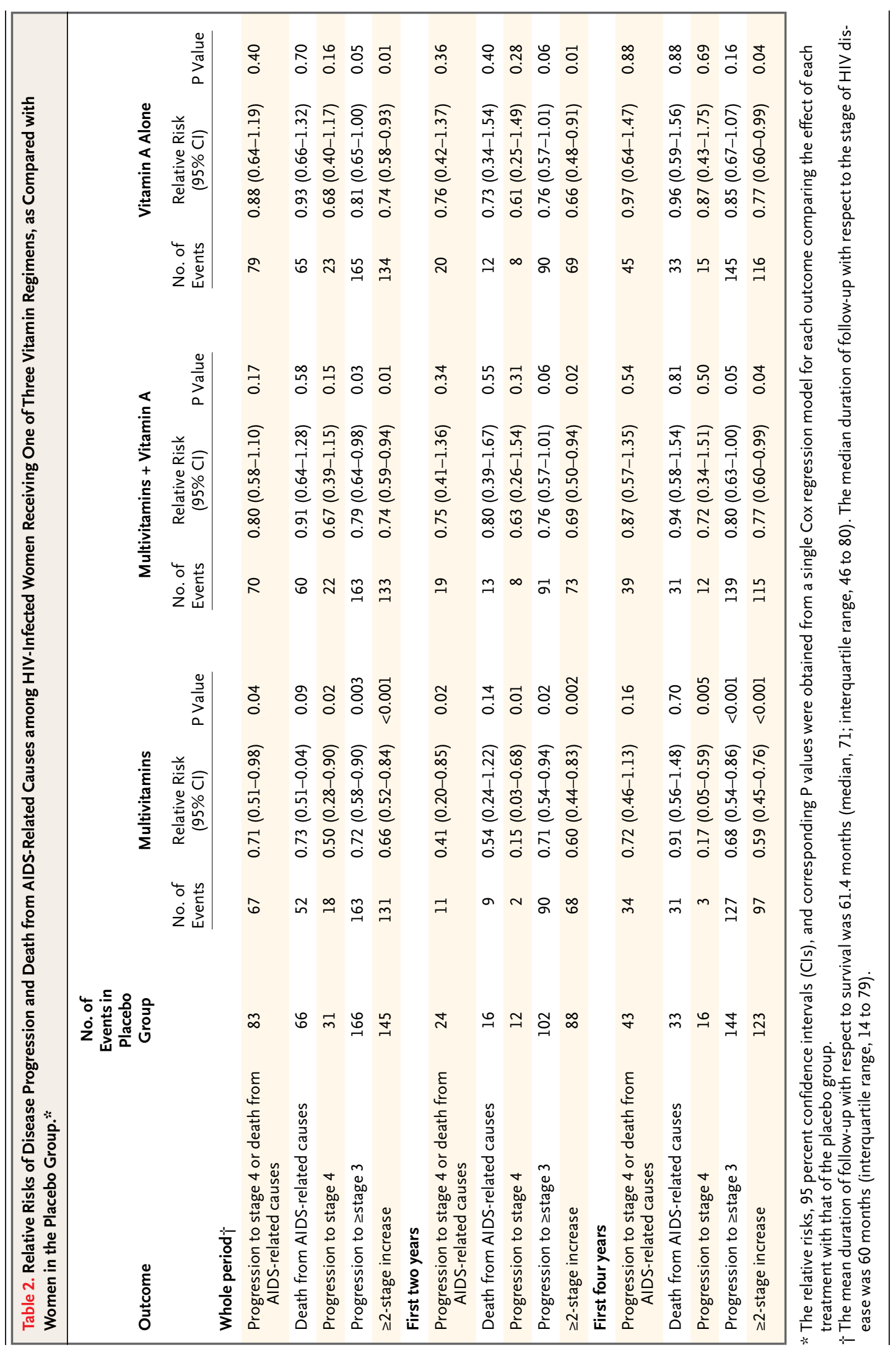


less likely to progress to WHO stage 4 or die of AIDS-related causes (relative risk, $0.71 ; 95$ percent confidence interval, 0.51 to $0.98 ; \mathrm{P}=0.04$ ) (Fig. 1 and Table 2). The effects of receiving vitamin $\mathrm{A}$ alone were smaller and for the most part not significantly different from those produced by placebo.

As compared with placebo, multivitamins also had beneficial effects on other outcomes of advanced disease, including the relative risk of progression to WHO stage $4(0.50$; 95 percent confidence interval, 0.28 to $0.90 ; \mathrm{P}=0.02$ ) or progression to stage 3 or higher $(0.72$; 95 percent confidence interval, 0.58 to $0.90 ; \mathrm{P}=0.003$ ). The effect of multivitamins was strongest in the first two years, although the beneficial effects were also observed at four years (Table 2). We found no evidence that the effects of multivitamins or vitamin A were significantly modified by baseline maternal nutritional status or CD4+ cell counts.

Multivitamins significantly reduced oral and gastrointestinal manifestations of HIV disease (Table 3). Other benefits included significant reductions in reported fatigue, rash, and acute upper respiratory tract infections. Vitamin A alone had no significant beneficial effects on any of these symptoms and signs.

Overall, the mean CD4+ cell counts were higher

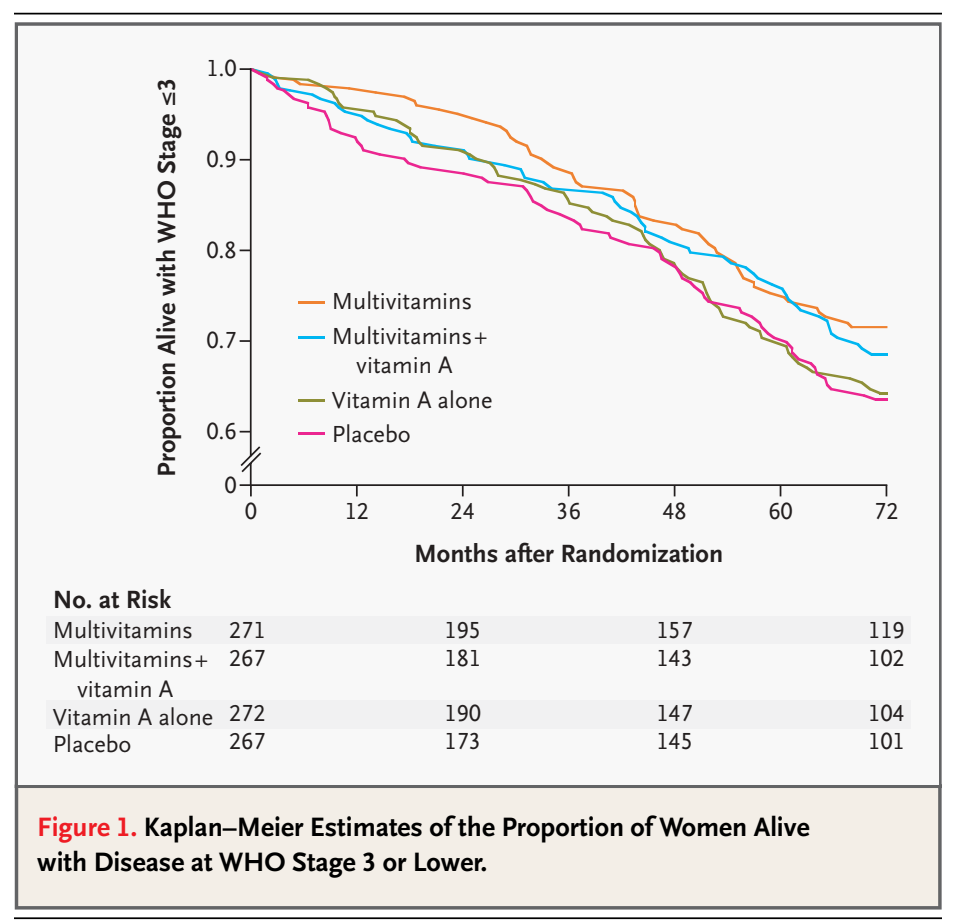

by 48 cells per cubic millimeter among women who received multivitamins than among those who received placebo ( 95 percent confidence interval, 10 to $85 ; \mathrm{P}=0.01$ ) (Table 4). The viral load was also significantly lower - by $0.18 \log (95$ percent confidence interval, -0.32 to $-0.03 ; \mathrm{P}=0.02)-$ among women who received multivitamins. Adding vitamin $A$ to the multivitamin regimen reduced the benefit with regard to the various end points examined.

In secondary analyses, we compared the use and nonuse of multivitamins and of vitamin A, using the factorial structure of the study. Women who received multivitamins were less likely to progress to WHO stage 4 or die of AIDS-related causes (relative risk, 0.80 ; 95 percent confidence interval, 0.64 to $1.01 ; \mathrm{P}=0.06$ ) than were women who did not receive multivitamins. In contrast, receipt of vitamin A, as compared with the absence of vitamin A supplementation, had no significant effect (relative risk, 0.99; 95 percent confidence interval, 0.79 to 1.24; $\mathrm{P}=0.90$; $\mathrm{P}$ for interaction between the two regimens $=0.27$ ). Similar results were noted for progression to stage 4 ( $\mathrm{P}$ for interaction $=0.11$ ), progression to stage 3 or higher ( $\mathrm{P}$ for interaction $=0.05$ ), and a two-stage increase ( $\mathrm{P}$ for interaction $=0.02$ ). In the first two years, multivitamin supplementation, as compared with no multivitamin supplementation, reduced the relative risk of progression to stage 4 or death from AIDS-related causes (0.66, $\mathrm{P}=0.08$ ), whereas vitamin A supplementation, as compared with no vitamin A supplementation, increased the relative risk $(1.07, \mathrm{P}=0.77$; and $\mathrm{P}$ for interaction $=0.07$ ). Multivitamins also significantly reduced all signs of complications, including oral ulcers (relative risk, $0.52 ; \mathrm{P}<0.001$ ), angular cheilitis (relative risk, $0.44 ; \mathrm{P}<0.001$ ), difficult or painful swallowing (relative risk, $0.47 ; \mathrm{P}<0.001$ ), dysentery (relative risk, $0.75 ; \mathrm{P}=0.03$ ), and fatigue (relative risk, 0.76; $\mathrm{P}=0.007)$. Women who received multivitamins also had significantly higher CD4+ cell counts (by 50 cells per cubic millimeter, $\mathrm{P}<0.001$ ) and lower viral loads (by $0.11 \log , \mathrm{P}=0.05$ ). In contrast, vitamin A supplementation, as compared with no vitamin A supplementation, increased the relative risks of angular cheilitis $(1.51, \mathrm{P}=0.04)$ and difficult or painful swallowing $(1.39, \mathrm{P}=0.02)$ and resulted in significantly lower CD8+ cell counts (by 46 cells per cubic millimeter, $\mathrm{P}=0.04$ ) and $\mathrm{CD} 3+$ cell counts (by 57 cells per cubic millimeter, $\mathrm{P}=0.03)$. 


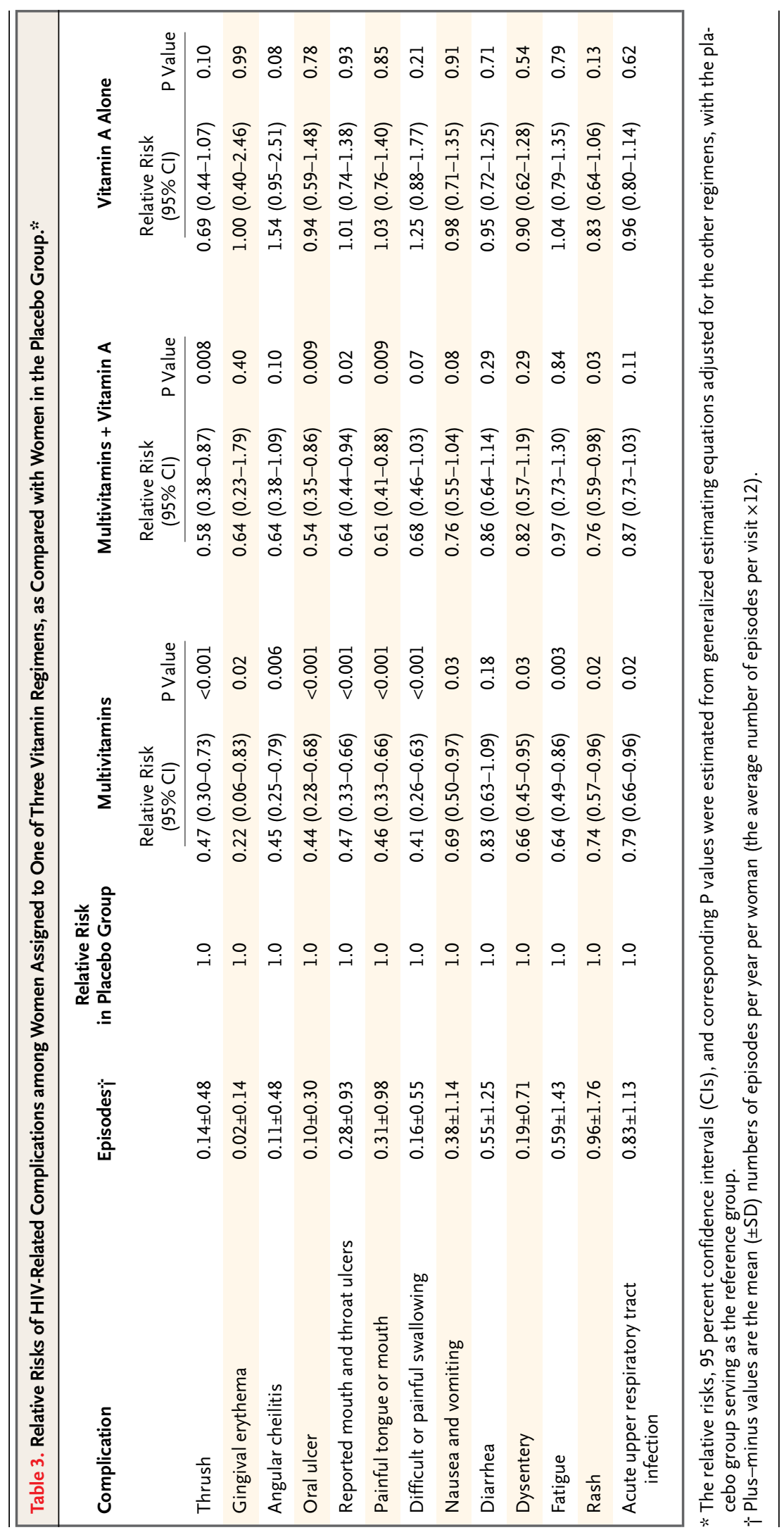

N ENGL J MED 351;1 WWW.NEJM.ORG JULY 1, 2004 


\section{DISCUSSION}

Multivitamin supplementation with vitamin B complex, vitamin C, and vitamin E significantly delayed the progression of disease among HIV-infected women, as reflected by the relative risk of progression to WHO stage 4 or death from AIDS-related causes, as well as other measures of disease progression. Supplementation with vitamin A alone had weaker effects that for the most part were not significantly different from those produced by placebo.

A relationship between suboptimal micronutrient status and multivitamin use and HIV progression has been noted in observational studies. In two longitudinal studies of U.S. men, ${ }^{12-14}$ higher intakes of vitamins (including vitamins $B_{1}, B_{2}$, and $\mathrm{B}_{6}$; niacin; vitamin $\mathrm{C}$; and vitamin $\mathrm{E}$ ) were associated with slower disease progression. Similarly, supplementation with B-complex vitamins was beneficial among black South Africans infected with HIV. ${ }^{15}$ U.S. men with lower serum vitamin E levels ${ }^{16}$ or vitamin $B_{12}$ levels ${ }^{17}$ were more likely than those with higher levels to have progression to AIDS. These findings from observational studies were questioned, given the potential for residual confounding by preclinical disease to explain the beneficial associations. ${ }^{3,4}$ In a recent study in Thailand, multivitamin supplementation was associated with a significant reduction in mortality among patients with baseline CD4+ cell counts below 100 cells per cubic millimeter but had no significant effects on CD4+ cell counts, viral load, or clinical disease progression. ${ }^{18}$ The statistical power of the study was limited by the relatively small sample size (481 patients and 23 reported deaths) and brief duration (48 weeks).

In our study, supplementation with multivitamins also reduced the incidence of complications including oral thrush, oral ulcers, and difficulty in swallowing, which are potential indicators of esophageal candidiasis and other inflammatory conditions. Nausea, vomiting, and diarrhea were also less frequent among women who received multivitamins. Oral and gastrointestinal manifestations are more likely in advanced stages of HIV disease

\begin{tabular}{|c|c|c|c|c|c|c|c|}
\hline \multirow[t]{2}{*}{ End Point } & \multirow[t]{2}{*}{$\begin{array}{c}\text { Mean Value } \\
\text { in Placebo Group* }\end{array}$} & \multicolumn{2}{|l|}{ Multivitamins } & \multicolumn{2}{|c|}{ Multivitamins + Vitamin A } & \multicolumn{2}{|c|}{ Vitamin A Alone } \\
\hline & & $\begin{array}{l}\text { Mean Difference } \\
(95 \% \mathrm{Cl}) \dagger\end{array}$ & PValue & $\begin{array}{l}\text { Mean Difference } \\
(95 \% \mathrm{Cl}) \dagger\end{array}$ & PValue & $\begin{array}{l}\text { Mean Difference } \\
\qquad(95 \% \mathrm{Cl}) \dagger\end{array}$ & PValue \\
\hline \multicolumn{8}{|l|}{ Whole period } \\
\hline $\mathrm{CD} 4+$ cell count $/ \mathrm{mm}^{3}$ & $449 \pm 255$ & 48 (10 to 85$)$ & 0.01 & 41 (4 to 77$)$ & 0.03 & $-15(-45$ to 14$)$ & 0.30 \\
\hline $\mathrm{CD} 8+$ cell count $/ \mathrm{mm}^{3}$ & $968 \pm 479$ & 43 (-15 to 101$)$ & 0.15 & $12(-44$ to 69$)$ & 0.67 & $-48(-100$ to 4$)$ & 0.07 \\
\hline $\mathrm{CD} 3+$ cell count $/ \mathrm{mm}^{3}$ & $1497 \pm 615$ & $88(14$ to 161$)$ & 0.02 & $47(-27$ to 120$)$ & 0.21 & $-72(-141$ to -3$)$ & 0.04 \\
\hline Viral load $(\log ) \Varangle$ & $4.67 \pm 0.86$ & $-0.18(-0.32$ to -0.03$)$ & 0.02 & $-0.07(-0.21$ to 0.09$)$ & 0.40 & $-0.03(-0.17$ to 0.11$)$ & 0.68 \\
\hline \multicolumn{8}{|l|}{ First 2 years } \\
\hline $\mathrm{CD} 4+$ cell count $/ \mathrm{mm}^{3}$ & $494 \pm 257$ & 48 (18 to 79$)$ & 0.002 & $21(-11$ to 53$)$ & 0.20 & $-16(-44$ to 13$)$ & 0.28 \\
\hline $\mathrm{CD} 8+$ cell count $/ \mathrm{mm}^{3}$ & $973 \pm 425$ & 56 (1 to 110$)$ & 0.05 & 40 (-18 to 97$)$ & 0.17 & $-36(-89$ to 17$)$ & 0.19 \\
\hline $\mathrm{CD} 3+$ cell count $/ \mathrm{mm}^{3}$ & $1544 \pm 587$ & 109 (32 to 185$)$ & 0.006 & $64(-15$ to 143$)$ & 0.11 & $-59(-132$ to 15$)$ & 0.12 \\
\hline Viral load $(\log ) \ddagger$ & $4.59 \pm 0.86$ & $-0.18(-0.34$ to -0.03$)$ & 0.02 & $-0.11(-0.27$ to 0.05$)$ & 0.17 & $-0.07(-0.23$ to 0.08$)$ & 0.35 \\
\hline \multicolumn{8}{|l|}{ First 4 years } \\
\hline $\mathrm{CD} 4+$ cell count $/ \mathrm{mm}^{3}$ & $470 \pm 254$ & 38 (8 to 68 ) & 0.01 & $19(-12$ to 50$)$ & 0.22 & -18 (-46 to 11$)$ & 0.22 \\
\hline $\mathrm{CD} 8+$ cell count $/ \mathrm{mm}^{3}$ & $959 \pm 438$ & 56 (2 to 111$)$ & 0.04 & 31 ( -26 to 87$)$ & 0.29 & $-53(-105$ to -1$)$ & 0.05 \\
\hline CD $3+$ cell count $/ \mathrm{mm}^{3}$ & $1506 \pm 584$ & 98 (25 to 171$)$ & 0.009 & 59 (-16 to 133$)$ & 0.12 & $-71(-140$ to -1$)$ & 0.05 \\
\hline Viral load (log) & $4.65 \pm 0.86$ & $-0.18(-0.33$ to -0.04$)$ & 0.01 & $-0.09(-0.24$ to 0.06$)$ & 0.24 & $-0.04(-0.18$ to 0.10$)$ & 0.57 \\
\hline
\end{tabular}

* Plus-minus values are means \pm SD. The baseline measurement was excluded.

$\dagger$ Values are the mean difference between this group and the placebo group. The mean differences, 95 percent confidence intervals (Cls), and corresponding $\mathrm{P}$ values were estimated from generalized estimating equations, after adjustment for baseline measurements. † $\mathrm{A}$ base-10 scale was used. 
and could interfere with patients' appetite and total energy intake in addition to decreasing their quality of life. ${ }^{19,20}$ Micronutrients may protect the integrity of oral and gastrointestinal epithelia and enhance local and systemic immunity. ${ }^{21}$

We observed significantly higher CD4+, CD8+, and $\mathrm{CD} 3+$ cell counts and lower viral loads among women who received multivitamins than among those who received placebo. $\mathrm{B}$ vitamins and vitamins $C$ and $E$ enhance cellular immunity. ${ }^{22,23}$ Significant positive relationships were observed between levels of several B vitamins and CD4+ cell counts among HIV-infected men in the United States. ${ }^{12,24}$ Vitamins enhance immune function, as measured by the levels of antiinflammatory cytokines. ${ }^{25} \mathrm{HIV}$-positive African women with no clinical manifestations had a vigorous antiinflammatory cytokine response. ${ }^{26}$ We previously reported that multivitamins significantly improved CD4+, $\mathrm{CD} 8+$, and $\mathrm{CD} 3+$ cell counts up to one year after randomization. ${ }^{11}$ Our updated findings indicate that this beneficial effect was sustained for a median of five years.

In addition to enhancing immunity, multivitamins may also reduce HIV replication, as indicated by the significant reduction in viral load. HIV replication in vitro is increased by oxidative stress. ${ }^{27}$ Components of our multivitamin supplement, particularly vitamins $\mathrm{C}$ and $\mathrm{E}$, are potent antioxidants. In a small, randomized, placebo-controlled study of 49 HIV-positive patients, those who received daily supplements of both vitamin E (800 IU) and vitamin C (1000 mg) for three months had a significant reduction in lipid peroxidation (a measure of oxidative stress), with a trend toward a reduced viral load. ${ }^{28}$

The benefits with respect to immunologic and virologic outcomes in our study were small relative to the effects of triple antiretroviral therapy. However, the effects of multivitamins on the CD4+ cell counts and viral load were similar to, and in some cases larger than, those of early trials, which compared therapy with a single antiretroviral agent with placebo or dual therapy with single-drug treatment, as well as recent trials comparing three-drug therapy with two-drug therapy. ${ }^{29}$ In a meta-analysis of studies that evaluated treatment-mediated changes in CD4+ cell counts and viral load as surrogates for the progression of HIV disease (progression to AIDS or death), the relationships between these markers and the risk of progression were linear. ${ }^{30}$
Applying our observed reduction of $0.18 \log$ in the viral load to this linear relation results in an increase in the time to progression to AIDS or death of approximately 30 percent, similar to the size of the effect that we observed.

Vitamin A alone had no significant effects on clinical outcomes, T-cell counts, or viral load. Among HIV-infected U.S. men, the relationship between vitamin A intake and HIV disease progression and mortality was $U$-shaped, suggesting that both low and high levels of intake are potentially harmful. ${ }^{13,14}$ We previously reported that vitamin A supplements resulted in a significant increase in mother-to-child transmission of HIV.7,8 Moreover, in the current study, we found that adding vitamin A to the multivitamin supplement apparently reduced the benefit of the latter regimen, raising questions about the safety of including vitamin A in supplements recommended for HIV-infected adults.

The timing of the initiation of antiretroviral therapy is still controversial. The revised U.S. guidelines for adults recommend initiation when AIDS-related symptoms develop or, for asymptomatic adults, when CD4+ cell counts drop below 350 per cubic millimeter or plasma levels of HIV-type RNA exceed 55,000 copies per milliliter. ${ }^{31}$ As antiretroviral therapy becomes available in less-developed countries, many HIV-infected persons who do not meet these guidelines will be identified. Our data suggest that multivitamins delay the onset of disease progression and thus the time to the initiation of antiretroviral therapy. Introducing these supplements would preserve the use of antiretroviral drugs for later stages of the disease, avert adverse events associated with them, and significantly reduce treatment-related costs. The retail cost of a year's supply of the multivitamins we used in this trial is approximately $\$ 15$ per person, and wholesale prices are substantially lower. Given the impaired absorption and increased metabolic utilization of nutrients among HIV-positive persons, ${ }^{3}$ we used multiples of the recommended dietary allowances in doses that were high enough to maximize the likelihood of providing a beneficial effect but that were within safe levels. The minimal dose of multivitamins necessary for the best health outcomes among HIV-infected persons is not known. We suggest that supplementation with the doses used in this trial be considered for HIV-infected persons before the initiation of antiretroviral therapy. 
Supported by grants from the National Institute of Child Health and Human Development (R01 32257) and the Fogarty International Center, National Institutes of Health. Hoffmann-La Roche donated the raw materials that were used to prepare the vitamin and placebo tablets.

We are indebted to the mothers and children; to the field teams, including nurses, midwives, supervisors, laboratory staff, and the administrative staff, who made the study possible; to Said Aboud, Gretchen Antelman, Illuminata Ballonzi, Beth Chaplin, Jenny Coley, Mary Kay Smith Fawzi, Ellen Hertzmark, Sylvia Kaaya, Eligius Lyamuya, Karim Manji, Nuala McGrath, Heavengton Mshiu, Miriam Mtawali, Christina Nyhus, Megan O'Brien, Boris Renjifo, Elmar
Saathoff, Willy Urassa, Walter Willett, and all other members of the Harvard-Tanzania collaboration for their input; to the members of the data and safety monitoring board - Graham Colditz, Nicholas Horton, Valerian Kimati, Kenneth McIntosh, Marcello Pagano (Chair), and Abby Shevitz; to Anne Willoughby at the National Institute of Child Health and Human Development for her valuable support; to Ken Bridbord at the Fogarty International Center of the National Institutes of Health; and to the authorities at Muhimbili University College of Health Sciences, Muhimbili National Hospital, the City of Dar es Salaam Regional Health Authority, and the Tanzanian National AIDS Control Program for their institutional support.
REFERENCES

1. UNAIDS. AIDS epidemic update: December 2003. (Accessed June 4, 2004, at http://www.unaids.org.)

2. Treating 3 Million by 2005 Initiative. Treating 3 Million by 2005: making it happen: the WHO strategy. Geneva: World Health Organization, 2003.

3. Semba RD, Tang AM. Micronutrients and the pathogenesis of human immunodeficiency virus infection. Br J Nutr 1999;81 181-9.

4. Fawzi WW. Micronutrients and human immunodeficiency virus type 1 disease progression among adults and children. Clin Infect Dis 2003;37:Suppl 2:S112-S116.

5. Fawzi WW, Msamanga GI, Spiegelma D, Urassa EJN, Hunter DJ. Rationale and design of the Tanzania Vitamin and HIV Infection Trial. Control Clin Trials 1999;20:75 90.

6. World Health Organization. Interim proposal for a WHO staging system for HIV infection and disease. Wkly Epidemiol Rec 1990;65:221-4.

7. Fawzi W, Msamanga G, Hunter D, et al. Randomized trial of vitamin supplements in relation to transmission of HIV-1 through breastfeeding and early child mortality. AIDS 2002;16:1935-44.

8. Fawzi W, Msamanga G, Antelman G, et al. Effect of prenatal vitamin supplementation on lower-genital levels of HIV type 1 and interleukin type 1 beta at 36 weeks of gestation. Clin Infect Dis 2004;38:716-22.

9. Cox DR. Regression models and life tables. J R Stat Soc (B) 1972; 34:187-220.

10. Diggle P, Liang KY, Zeger SL, eds. Analy sis of longitudinal data. Oxford, England Oxford University Press, 1995.

11. Fawzi WW, Msamanga GI, Spiegelman D, et al. Randomised trial of effects of vitamin supplements on pregnancy outcomes and $\mathrm{T}$ cell counts in HIV-1-infected women in Tanzania. Lancet 1998;351:1477-82.

12. Abrams B, Duncan D, Hertz-Picciotto I. A prospective study of dietary intake and ac- quired immune deficiency syndrome in HIV-seropositive homosexual men. J Acquir Immune Defic Syndr 1993;6:949-58.

13. Tang AM, Graham NMH, Kirby AJ, McCall AD, Willett WC, Saah AJ. Dietary micronutrient intake and risk progression to acquired immunodeficiency syndrome (AIDS) in human immunodeficiency virus type 1 (HIV-1)-infected homosexual men. Am J Epdemiol 1993;138:937-51.

14. Tang AM, Graham NMH, Saah AJ. Effects of micronutrient intake on survival in human immunodeficiency virus type 1 infection. Am J Epidemiol 1996;143:1244-56 15. Kanter AS, Spencer DC, Steinberg MH Soltysik R, Yarnold PR, Graham NM. Supplemental vitamin $\mathrm{B}$ and progression to AIDS and death in black South African patients infected with HIV. J Acquir Immune Defic Syndr 1999;21:252-3.

16. Tang AM, Graham NMH, Semba RD, Saah AJ. Association between serum vitamin A and E levels and HIV-1 disease progression. AIDS 1997;11:613-20.

17. Tang AM, Graham NMH, Chandra RK, Saah AJ. Low serum vitamin B-12 concentrations are associated with faster human mmunodeficiency virus type 1 (HIV-1) disease progression. J Nutr 1997;127:345-51.

18. Jiamton S, Pepin J, Suttent R, et al. A randomized trial of the impact of multiple micronutrient supplementation on mortality among HIV-infected individuals living in Bangkok. AIDS 2003;17:2461-9.

19. Greenspan D, Komaroff E, Redford M et al. Oral mucosal lesions and HIV vira oad in the Women's Interagency HIV Study (WIHS). J Acquir Immune Defic Syndr 2000 25:44-50.

20. Lorenz KA, Shapiro MF, Asch SM, Boz zette SA, Hays RD. Associations of symptoms and health-related quality of life: findings from a national study of persons with HIV infection. Ann Intern Med 2001;134: 854-60

21. Cunningham-Rundles S. Nutrition and the mucosal immune system. Curr Opin Gastroenterol 2001;17:171-6.

22. Bendich A, Cohen M. B vitamins: effects on specific and nonspecific immune responses. In: Chandra RK, ed. Nutrition and immunology. New York: Alan R. Liss, 1988: 101-23.

23. Bendich A. Antioxidant vitamins and immune responses. In: Chandra RK, ed. Nutrition and immunology. New York: Alan R. Liss, 1988:125-47.

24. Baum MK, Shor-Posner G, Lu Y, et al. Micronutrients and HIV-1 disease progression. AIDS 1995;9:1051-6.

25. Grimble RF. Nutritional modulation of cytokine biology. Nutrition 1998;14:634-40. 26. Thea DM, Porat R, Nagimbi K, et al. Plasma cytokines, cytokine antagonists, and disease progression in African women infected with HIV-1. Ann Intern Med 1996; 124:757-62.

27. Schreck R, Rieber P, Baeuerle PA. Reactive oxygen intermediates as apparently widely used messengers in the activation of the NF-kappa B transcription factor and HIV-1. EMBO J 1991;10:2247-58.

28. Allard JP, Aghdassi E, Chau J, et al. Effects of vitamin $\mathrm{E}$ and $\mathrm{C}$ supplementation on oxidative stress and viral load in HIV-infected subjects. AIDS 1998;12:1653-9.

29. Jordan R, Gold L, Cummins C, Hyde C. Systematic review and meta-analysis of evidence for increasing numbers of drugs in antiretroviral combination therapy. BMJ 2002;324:757-67.

30. HIV Surrogate Marker Collaborative Group. Human immunodeficiency virus type 1 RNA level and CD4+ count as prognostic markers and surrogate end points: a meta-analysis. AIDS Res Hum Retroviruses 2000;16:1123-33.

31. AIDSinfo Website. Guideline for the use of antiretroviral agents in HIV-1 infected adults and adolescents. (Accessed June 4, 2004, at http://aidsinfo.nih.gov.)

Copyright (@) 2004 Massachusetts Medical Society. 